\title{
Automatic Cotton Seed Sowing Machine
}

\author{
Sauravsing Rajput ${ }^{1}$, Suraj Shinde ${ }^{2}$, Himanshu Chaudhari ${ }^{3}$, Mayur Somvanshi ${ }^{4}$, Tushar A. Koli ${ }^{5}$ \\ ${ }^{1,2,3,4}$ UG students, Mechanical Engineering, GCOE, Jalgaon, India \\ ${ }^{5}$ Assistant Professor, Mechanical Engineering, GCOE, Jalgaon, India
}

Received on: 16 July, 2021

Revised on: 15 August, 2021

Published on: 17 August, 2021

\begin{abstract}
Cotton seed sowing is the process of placing seed in farm at specific distance, depth and quantity of seeds. Cotton seed are costlier thus it is very important for farmers to check for no wastage of seeds. Thus farmers in India prefer manual method of cotton seed sowing. Manual seed sowing has its own demerits such as it is hard to achieve specific seed placement, spacing efficiencies and labors face physical problems. For this reason to achieve perfection in seed placing a machine has to be developed which will solve all this problems and drudgery involved in manual sowing method. This machine should be suitable for all type of farms, simple in construction and easy to use, carry out maintenance. Handling and operating of this machine is easy to understand to all. The aim of the paper is to study all the mechanisms used in this machine and design factor that need to be considered before building this machine. Additionally, problem we faced during making of this machine.
\end{abstract}

Keywords- Seed Sowing, Cotton Seed Sowing, Low Cost, Less Maintenance

\section{I -INTRODUCTION}

$\mathrm{I}_{\mathrm{n}}$ ndia is the world's largest producer of milk, pulses and jute, and ranks as the second largest producer of rice, wheat, sugarcane, groundnut, vegetables, fruit and cotton. Regardless of Indian agriculture sector accounting for $23 \%$ of GDP, it is overlooked by majority of sector in term of technological advancement. Cotton production in India covers around 125.84 lakh hectare of land. For making land ready for cotton production it is important to follow proper methods. The first method of cotton production is to prepare the land for planting by creating furrows in the soil. With the help of direct water irrigation and furrows, the soil warms faster. After the soil is ready for planting, Farmers will plant the seed in the soil. This process consumes lots of time and also farmers have to rely on labors. The time required for this process is more thus cost of labors also increases. Lack of labors causes increase in actual operation periods and leads to production losses. The conventional seed sowing machine and previous inventions are less efficient. To meet the future food demands, the farmers have to implement the new techniques which will not affect the soil texture but will increase the overall crop production. There are many advance machines available for all types of seed sowing but none of them suits for cotton seed sowing as the seeds are quiet expensive. Cotton is the most important plant fiber to make textile products. Even though it is cultivated by many countries, it is hard to find perfect cotton seed sowing machine.This paper deals with the new modern machine which will enhance overall performance in cotton farming and less costing.

\section{II- LITERATURE REVIEW}

Traditional sowing method of cotton seed has many limitations. It is impossible to achieve uniformity in seed distribution and also uneven depth of seed placement. One other limitation is that it is important that labor should get available on time and labor are quiet expensive. Sometimes labors face back pain while working continuously. 


\section{International Journal of Innovations in Engineering and Science, www.ijies.net}

To avoid facing these problems, it is important for farmers to use modern machinery which is less expensive and less time consuming.

New proposed machine has number of advantages over traditional methods. With the help of this machine farmers can

1) Achieve constant seed flow rate thus avoiding wastage of seed,

2) Avoid affecting soil texture

3) Achieve same row spacing and seed spacing and

4) Achieve constant depth of seed placing and avoid putting pressure on seed.

\section{III- METHODOLOGY}

Proposed work started with studying the requirement of farmers and the existing method of agriculture seed planter. By collecting all this information we started finding solutions. This study will include overview of automatic seed sowing machine which has been built to solve the entire problem occurring while Cotton seed sowing process. Seed sowing machine is the cheapest and fastest way to improve productivity and reducing expenses.

This work has been separated in 3 stages fist stage is to make body (Frame) second stage is to make transmission system third stage is to make hopper and seed collector mechanism and last stage is to make furrow mechanism.

Table 1-Dimension and material chart

\begin{tabular}{|c|c|c|c|c|}
\hline $\begin{array}{c}\text { Sr. } \\
\text { No. }\end{array}$ & Part name & Dimension & Material & Nos. \\
\hline 1 & Body & $30 " \times 36 "$ & CS & 1 \\
\hline 2 & Wheel & $18.11 ”$ & CS & 4 \\
\hline 3 & Axel & 38 "20Ø & CI & 2 \\
\hline 4 & Hollow Axel & $32 " 20 \varnothing$ & CI & 1 \\
\hline 5 & Pulley & $3 "$ A & CI & 3 \\
\hline 6 & Pulley & $6 " \mathrm{~A}$ & CI & 1 \\
\hline 7 & Belt & $31 " \mathrm{~A}$ & Rubber & 1 \\
\hline 8 & Belt & $32 " \mathrm{~A}$ & Rubber & 1 \\
\hline 9 & Furrow & - & Sheet Metal & 1 \\
\hline
\end{tabular}

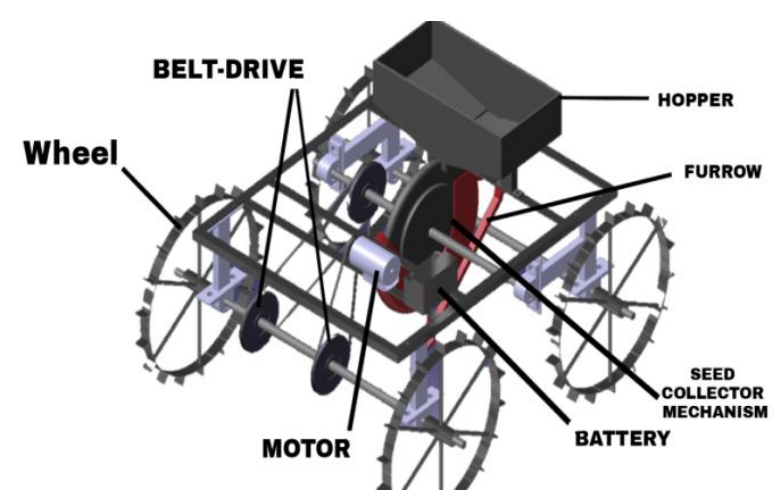

Fig. 1 3-D Model of Cotton Seed Sowing Machine
This machine is made with four types of mechanism. All this mechanisms play crucial role in working of this machine. All this mechanism is given below:-

1) Body:-

Body dimensions: -30 inches $\times 36$ inches

Ground clearance: - 9.5 inches

Body Weight: - 70 - $80 \mathrm{~kg}$ approx.

Wheels dimensions:-

We had to consider few conditions before selecting all this parameters. These conditions include vertical and horizontal lining of farm in which we are planting seeds. We selected ground clearance of frame depending on all other mechanism which we were going to attach on this machine. Body weight was slightly going above our expectations due to unavailability of proper materials in market. We used iron rods, angle sections, and square section for fabrication of this machine. This body is designed in such a way that it can be easily dismantled and can be modified easily.

\section{2) Transmission mechanism:-}

Battery Specification: - $33 \mathrm{Ah} / 12 \mathrm{~V}$

Motor Specification: - 1.5 HP (3100 RPM) $\times 2$

Pulley dimensions: - 2 inches (Driver) and 6 inches (Driven)

Belt size: - 31 inches and 32 inches

Our transmission is based on EV system that is battery operated vehicle. Components of transmission system include motor, battery and pulley belt assembly. We have used few easy calculations of battery and motor selection for finding out best suitable equipment. Even though we faced troubles during our first trial of transmission mechanism, this problem basically had to do with torque requirement. Motor we chose was running on RPM 3100 but it had no capacity to push loaded vehicle so we decided to use two motors of same rpm capacity. Using separate power supply to both motor it gave correspond rpm and hence good torque carrying capacity.

\section{3) Seed metering mechanism:-}

Seed metering mechanism plays crucial role in this project and it was the hardest part of project as it has to do with timing. This seed metering plate is held together with hopper in such a way that seed will not escape from hopper so that there will be no seed wastage. Seed metering plate was rotated by means of belt drive. This belt drive was driven by means of driving axle, which means it will rotates in same speed as vehicle speed. 


\section{International Journal of Innovations in Engineering and Science, www.ijies.net}

This plate has holes drilled in it which depends in farmer's requirement i.e. if farmer's wants to plant two seed to be dropped, this plate will have two holes at a same place. This plate will drop seed on every half rotation at a distance of 2 feet.

\section{4) Furrow or Digger Mechanism:-}

Furrow has two main functions, one is to dig hole and another is to put seed in soil. Furrow is designed in such a way that it will dig a hole about 1.5 inches. It has pipe connected on it through which seed will be dropped from seed collector mechanism. This seed will be directly dropped in hole dig by furrow.

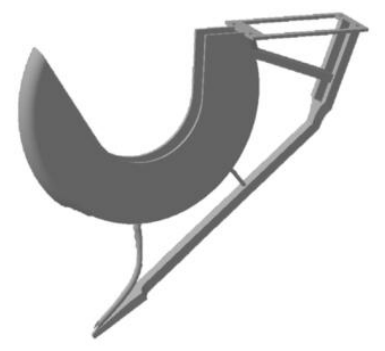

Fig. 2 3-D Model of Furrow

This furrow has to be light in weight but it should withstand all shocks and vibrations. This mechanism has shield made on it which prevent seed from seed collector mechanism to drop anywhere else and prevent wastage of seeds. This shield is made in such a way that seed collector plate fits into it. This plate is made of metal sheet.

\section{IV-DESIGN}

\section{Design for Battery Selection for vehicle}

For selection of motor drive we need to find out power output requirement

To calculate,

Power $(\mathrm{P})=$ Force $^{*}$ Velocity

$$
\text { Force }=\text { Weight }
$$

Weight $=$ Mass $*$ acceleration due to gravity

Hence,

Power $(\mathrm{P})=$ mass $*$ Acceleration $*$ Velocity

Actual weight of Whole structure is around $60 \mathrm{~kg}$, so assume $30 \%$ more weight. So, assume actual weight of structure $80 \mathrm{~kg}$ and speed required for vehicle to run is $10 \mathrm{~km} / \mathrm{hr}$ i.e. $2 \mathrm{~m} / \mathrm{s}$

Using formula for Power calculation,

$$
\begin{aligned}
& \square \text { Power }(P)=\text { Mass } \times \text { Acceleration } \times \text { Velocity } \\
& \square \text { Power }(P)=80 \mathrm{~kg} \times 9.81 \mathrm{~m} / \mathrm{s}^{2} \times 2 \mathrm{~m} / \mathrm{s} \\
& \square \operatorname{Power}(P)=1569.6 \mathrm{watt}
\end{aligned}
$$

Calculate require HP of motor,

$$
\begin{aligned}
& \square \text { Horsepower }(H P)=\frac{p}{746} \\
& \square \text { Horsepower }(H P)=\frac{15696}{746} \\
& \square \text { Horsepower }(H P)=2.10 \mathrm{hp}
\end{aligned}
$$

\section{Calculating Wheel speed:-}

Required speed 10km/hour i.e. 6.21 miles/hour Wheel radius $=0.23$ meter

Step 1) Converting miles/hour in meter/hour

$$
\begin{aligned}
& 6.21 \times 1609=9991.89 \text { meter } / \text { hour } \\
& \frac{9991.89}{60}=166.5315 \mathrm{~meter} / \mathrm{min}
\end{aligned}
$$

Step 2) Circumference of wheel-

$$
\begin{aligned}
& C=2 \pi r \\
& C=2 \times 3.14 \times 0.23 \\
& C=1.44 \text { meter }
\end{aligned}
$$

Step 3) Calculate wheel speed in RPM

$$
\begin{aligned}
& R P M=\frac{\text { Speed in meter per min }}{\text { Circumference in meter }} \\
& R P M=\frac{166.5315}{1.44} \\
& R P M \cong 116
\end{aligned}
$$

\section{Pulley selection to obtain required Speed:-}

Belt Length 32 15/16" 
Vol. 6 , No. 10, 2021, PP. 112- 115

\section{International Journal of Innovations in Engineering and Science, www.ijies.net}

Ratio 1:3

RPM Small 3000

RPM Large 1000

Belt Speed $1570.8 \mathrm{ft} / \mathrm{min}$

Pulley Gap 6"

So, Obtained RPM is 1000

\section{V- FUTURE SCOPE}

This machine has some limitations as it can perform only one task, which is sowing in one row at a time. But this machine has few advantages like it can be easily upgraded to multi-tasking. Modification that we can do on this machine is given below-

1) We can mount pesticide sprayer on both hand side of this machine.

2) We can mount two or more seed collector so that it can complete maximum rows at a time.

3) We can upgrade its power transmission so that it can give maximum efficiency.

4) We can add steering mechanism.

\section{VI- CONCLUSION}

Proposed seed sowing machine is made to fulfill necessary requirement of cotton producing farmers. This machine can also be upgraded depending on other requirement of farmers. As this machine is made out of scrap materials, it is affordable for all rank of farmers and also it is easy to maintain. This machine has potential to carry out work in all types of field. This machine can be easily modified according to farmers need. By using this machine, flexibility of distance, depth variation and seed quantity can be achieved.

\section{REFERENCES}

[1] Joseph M. Rickey (2013),"A methodology for design for Seed sowing machine", Research, Vol. 10, No. 1, 1 pp. $139-155$.

[2] Vaibhav Thorat, Badal Autade, Tushar Jagtap, Krishna Abhale, Kishor Kumbharde "Study Of Multiple Seed Planting Machine". International Research Journal of Engineering and Technology (IRJET) ISSN: 2395-0056 Volume: 05 Issue: 01 | Jan-2018 Pp.1146-1149.
[3] F.W.Gerard A.K. (1998), "multipurpose seed sowing machine", Journal of Retailing and Consumer 10. Blischke, W.R. and Murthy, D.N.P. (2000), Reliability: Modeling, Prediction, and Optimization, John Wiley and Sons Inc., New York.

[4] Roshan V Marode and Gajanan P Tayade, Design And Implementation Of Multi Seedsowing Machine, International Journal of Mechanical Engineering And Robotics Research, Vol. 2, No. 4, October 2013. Fl. Loghin Et Al, Dynamic Modeling Of Technical System Tractor

[5] K. Saravanan, S. P. Sundar Singh Sivam, S. RajendraKumar, K. SathiyaMoorthy, "Design and Fabrication of Automatic Seed Sowing Robot for Agricultural Field". International Journal of Pure and Applied Mathematics ISSN: 1314-3395 Vol-120 No. 6 2018, 11749-11766

[6] Amol Magar, Rahul Jadhav, Prakash Solunke, Amol Borade, Gaurav Jadhav, Nagesh Dongare, "Cotton Seed Sowing Machine". IJARIIE-ISSN(O)-2395-4396, Vol-3 Issue-3 2017

[7] Kiran K. Jadhav, Avdhoot S. Narote, Pavan U. Shelke, Vishal N. Alladwar, Akshay S. Dhuldhule, "Mechanization of Mannually Operated Seed Sowing Machine for small farming land". International Journal of Advanced Research Trends in Engineering and Technology (IJARTET) ISSN 2394-3785 Vol.6, Issue 5, May 2019 